\title{
Interaction between synoviocytes and extracellular matrix in vitro
}

\author{
Steven E Carsons, Joyce Wolf
}

Synoviocyte adhesion, migration, and proliferation are essential in the growth of pannus and the subsequent invasion of cartilage in inflammatory arthritis. These cellular functions are regulated by the extracellular matrix. ${ }^{1}$ In vitro studies of synoviocytes have previously demonstrated that they display abnormal phenotypic properties, including a transformation-like morphology manifested by cell overlapping and focus formation. ${ }^{23}$ Abnormal synoviocyte phenotype has been shown to be strongly influenced by extracellular matrix; synoviocytes exhibit extensive focus formation when plated on exogenous fibronectin rich matrices or when primed to switch endogenous matrix production from a collagen enriched to a fibronectin enriched type. ${ }^{3}$ To determine if the influence of matrix on synoviocyte morphology is associated with effects on synoviocyte adhesion and growth, we studied the effect of purified matrix components and a cell free matrix preparation isolated from human synovium on the attachment, spreading, and proliferation of human synoviocytes in vitro.

\section{Materials and methods}

CELL CULTURE IN SERUM FREE MEDIUM

Synovial samples obtained from patients undergoing total knee replacement surgery for rheumatoid arthritis were placed in explant culture in serum free medium consisting of a 1:1 mixture of Dulbecco's modified Eagle's medium (DMEM) and F12 supplemented with insulin $5 \mu \mathrm{g} / \mathrm{ml}$, hydrocortisone $5 \mu \mathrm{g} / \mathrm{ml}$, epidermal growth factor $5 \mathrm{ng} / \mathrm{ml}$, transferrin $20 \mu \mathrm{g} / \mathrm{ml}$, bovine serum albumin (BSA) $2.5 \mathrm{mg} / \mathrm{ml}$, and penicillin/streptomycin.

GROWTH AND MORPHOLOGY

To determine cell growth, cells were treated with $0.05 \%$ trypsin and $0.53 \mathrm{mmol} / \mathrm{l}$ EDTA (Gibco) for one minute. Trypsinisation was stopped with $0 \cdot 1 \%$ soya bean trypsin inhibitor (Sigma). Cells were then suspended in growth medium and plated at $2 \times 10^{4}$ cells/well in 24 well dishes (Corning). Some wells were coated with extracellular matrix proteins as described below. The DNA content of the wells was determined by the fluorimetric method of West et al. ${ }^{4}$ The morphology of cells grown in wells was observed and photographed using a Nikon Labophot system.
CELL ATTACHMENT ASSAY

Cells labelled with carbon-14 amino acids (1 $\mu \mathrm{Ci} / \mathrm{ml}$; New England Nuclear NEC44SE) were harvested with trypsin as above, washed in DMEM containing $0 \cdot 25 \% \mathrm{BSA}$ and plated at $2 \times 10^{4}$ cells/well in 24 well dishes for 60 minutes at $37^{\circ} \mathrm{C}$. Non-adherent cells were removed by washing with phosphate buffered saline (PBS) and adherent cells were lysed with $0.1 \mathrm{ml}$ of $1 \%$ sodium dodecyl sulphate. One hundred microlitres of lysate was added to $1 \mathrm{ml}$ of Ecoscint and counted using a Beckman LS-9000 scintillation counter.

EXTRACELLULAR MATRIX PREPARATIONS Fibronectin was isolated from outdated, citrated human plasma as previously described. $^{5}$ Type I collagen was purchased from Collaborative Research. Microtitre plate wells were coated with fibronectin $(100 \mu \mathrm{g} / \mathrm{ml})$ or type I collagen $(2.5 \mathrm{mg} / \mathrm{ml})$ in PBS for 16 hours at $4^{\circ} \mathrm{C}$. Fibronectincollagen complexes were formed by adding fibronectin solution to type I collagen coated wells for 60 minutes at $23^{\circ} \mathrm{C}$. Extracellular matrix fibres were isolated from rheumatoid synovial tissue by a modification $^{6}$ of the method of Rojkind et al. ${ }^{7}$ The peptides Arg-Gly-Asp-Ser (RGDS) and ArgGly-Glu-Ser (RGES) were obtained from Sigma.

ANTIFIBRONECTIN ANTIBODY

Antifibronectin antiserum was purchased from Organon-Technika. Antifibronectin IgG and IgG from normal rabbit serum were isolated by sequential chromatography on DEAE-Sephacel and Protein A-Agarose. Fab' fragments were prepared by digestion of purified normal rabbit IgG or antifibronectin IgG with papain and separated by chromatography on Protein A-Agarose.

FIBRONECTIN FRAGMENTS

Plasma fibronectin was digested with Cathepsin D (Boehringer) at an enzyme:substrate ratio of $1: 50$ for 60 minutes at $30^{\circ} \mathrm{C}$. Carboxyterminal $140 \mathrm{kDa}$ cell binding fragments were separated from $70 \mathrm{kDa}$ amino-terminal collagen binding fragments by affinity chromatography on gelatin Sepharose. 


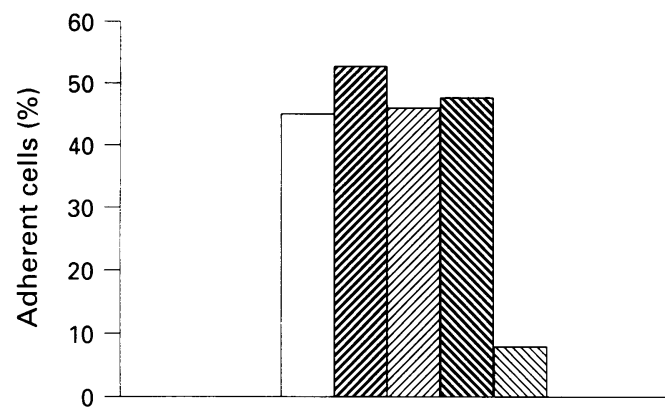

Figure 1 Attachment of synoviocytes to extracellular matrix preparations at 45 minutes. $\square=$ Synovial cell free matrix; $\mathbb{Z}$ purified plasma fibronectin; $\mathbb{Z}=$ collagen type I; $\mathbb{\$}=$ complex of type I collagen and fibronectin; $\mathbb{\Delta}=$ tissue culture plastic.

\section{Results}

SYNOVIOCYTE ATTACHMENT AND SPREADING Synoviocyte attachment to all matrix substrata was superior to attachment on tissue culture plastic. There were no significant differences of attachment to collagen I, fibronectin, fibronectin-collagen complexes, or synovial cell free matrix (SCFM): approximately $50 \%$ of cells were attached to matrix at 45 minutes (fig 1). However, only $30 \%$ of synoviocytes plated on plastic had become attached after one hour. When synoviocyte attachment to fibronectin was compared in parallel with the attachment of human laryngeal fibroblasts (LFB), LFB attachment was superior at 45 and 60 minutes (fig 2). Synoviocyte spreading was enhanced on fibronectin compared with the other matrix substrata. Spreading on all matrices was superior to that on tissue culture plastic (fig 3).

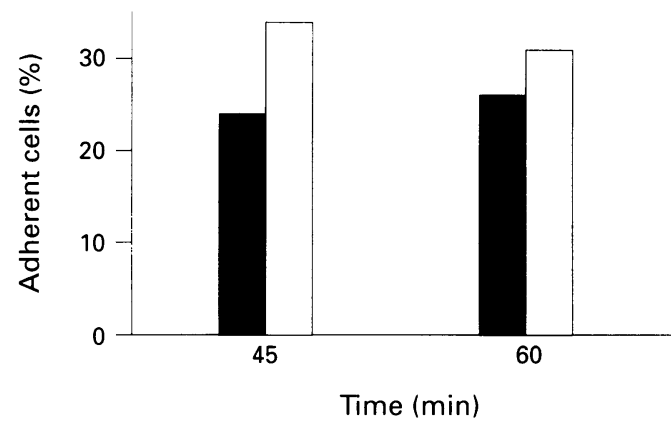

Figure 2 Adhesion assay comparing attachment of synoviocytes (syn 88-10) and laryngeal fibroblasts $\square$ (LFB p11) to purified plasma fibronectin at 45 and 60 minutes.

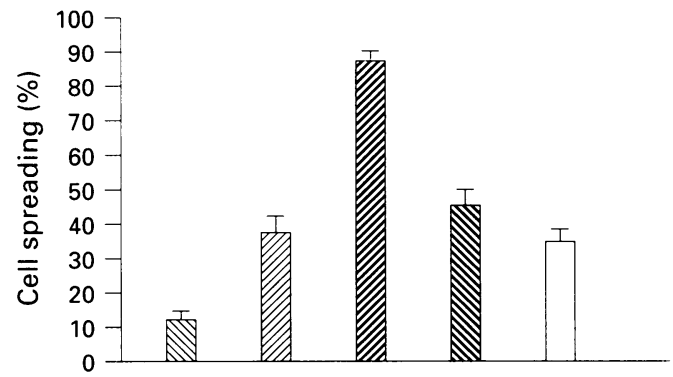

Figure 3 Spreading of synoviocytes on various matrix substrata. Spread cells appear elongate and have lost refractility under phase contrast microscopy. $\square=$ Synovial refractility under phase contrast microscopy. $\square=$ Synovial
cell free matrix; $\mathbb{Z}$ = purified plasma fibronectin; $\mathbb{Z}=$ type I collagen; $\mathbb{\$}=$ complex of type I collagen and fibronectin; $\mathbb{N}=$ tissue culture plastic.

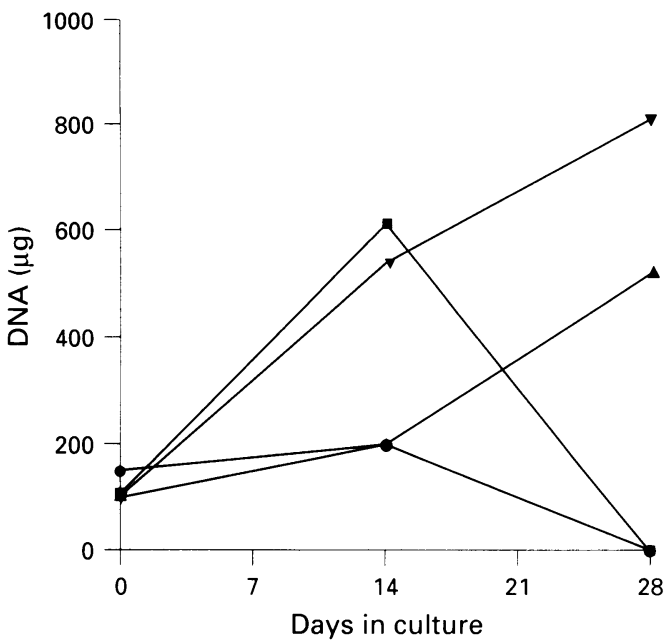

Figure 4 Proliferation of synoviocytes and laryngeal fibroblasts on tissue culture plastic and fibronectin substrata (all cells maintained in serum free medium for 28 days).

= Laryngeal fibroblasts in fibronectin coated wells;

$\boldsymbol{\nabla}=$ synoviocytes in fibronectin coated wells; $\mathbf{\theta}=$ laryngeal fibroblasts on plastic; $\mathbf{\Delta}=$ synoviocytes on plastic.

\section{SYNOVIOCYTE GROWTH}

Synoviocytes proliferated for at least 28 days on tissue culture plastic when maintained in serum free defined medium, whereas LFB did not (fig 4). HFL-1 fibroblasts also did not proliferate under these conditions (data not shown). Synoviocyte proliferation was enhanced by plating on all matrix substrata studied (fig 5). SCFM was similar to fibronectin, both matrices showing an approximately threefold increase in synoviocyte proliferation. Proliferation on collagen I enriched matrices was intermediate between that seen on fibronectin or SCFM and plastic; it was increased approximately two-fold.

LFB survived for 14 days under these culture conditions. When plated on extracellular matrices, these cells displayed enhanced proliferation only on fibronectin (fig 5). Specifically, they did not respond to the extracellular matrix purified from synovium (SCFM).

EFFECT OF FIBRONECTIN ANTIBODIES AND FRAGMENTS ON SYNOVIOCYTE GROWTH

Although plating cells on fibronectin enhanced proliferation, incubation of cultures with antifibronectin IgG added six hours after

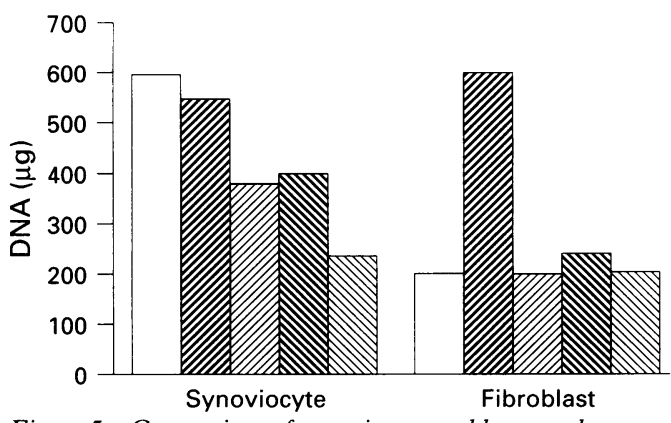

Figure 5 Comparison of synoviocyte and laryngeal fibroblast proliferation on various matrix substrata.
$\square=$ Synovial cell free matrix; $\square=$ purified plasma fibronectin; $\mathbb{Z}=$ type I collagen; $\mathbb{N}=$ type I collagenfibronectin complex; $\mathbb{\nabla}=$ plastic. 


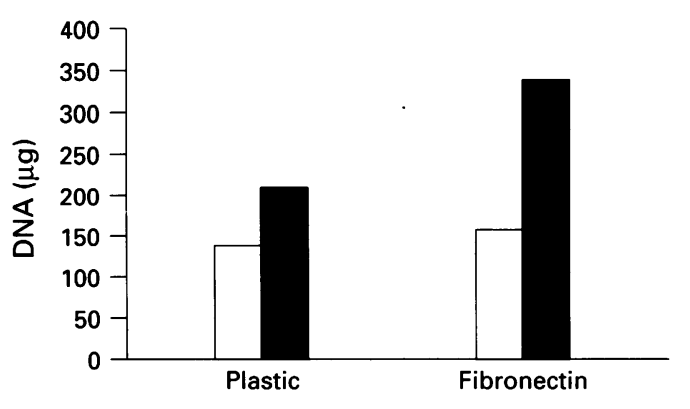

Substrate

Figure 6 Effect of purified antifibronectin IgG on synoviocyte proliferation on plastic and fibronectin. $\square=$ Purified normal rabbit IgG control; $\square=$ co-incubation of synoviocytes with anti-fibronectin IgG from day 1 to day 7 .

attachment was found to enhance proliferation further at 7-10 days (fig 6). Addition of antifibronectin Fab' fragment or addition of the $140 \mathrm{kDa}$ cathepsin $\mathrm{D}$ fibronectin fragment containing the cell binding domain resulted in an approximately $50 \%$ inhibition of cell growth (fig 7). Although antifibronectin Fab' and fibronectin $140 \mathrm{kDa}$ fragment produced similar growth inhibition (fig 8), cell morphology was different: synoviocytes treated with fibronectin $140 \mathrm{kDa}$ fragment were less well spread and appeared rounded, an appearance similar to that previously reported with RGDS treat-

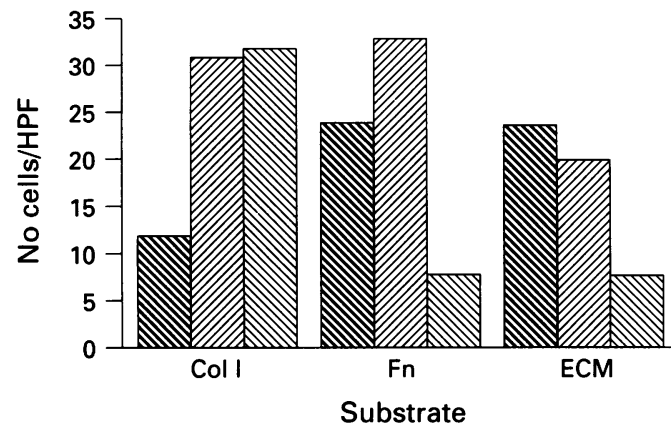

Figure 7 Effect of fibronectin fragments on growth of synoviocytes plated on different substrata and coincubated from day 1 to day 7 with $P B S$ ( $\mathbf{N})$, the fibronectin from day 1 to day 7 with $P B S(\mathbb{N})$, the frbronectin
$70 \mathrm{kDa}$ collagen binding fragment $(\square)$, or the fibronectin $140 \mathrm{kDa}$ cell binding fragment ( $\mathbb{})$. Col I = Type I collagen; $F n=$ purified plasma fibronectin; $E C M=$ extracellular matrix (synovial cell free). HPF = high power field.

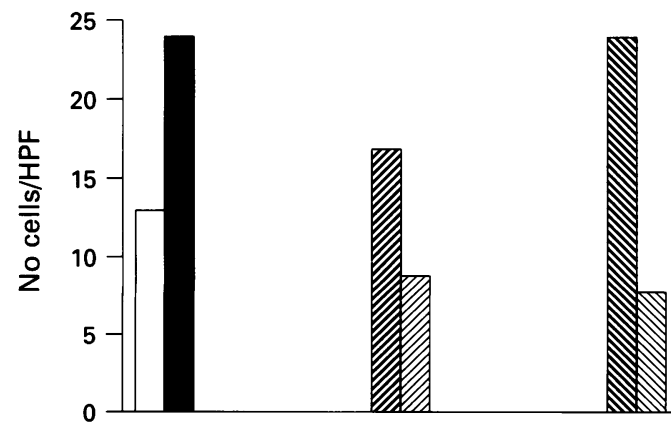

Figure 8 Effect of antifibronectin preparations on growth of synoviocytes plated on fibronectin and coincubated with antibodies or fibronectin peptides from day 1 to day 7 . $\square=$ Purified normal rabbit IgG control; $\square=$ purified antifibronectin IgG; $=$ purified normal rabbit IgG Fab' fragments; $\square=$ purified antifibronectin Fab' fragments; $\mathbb{N}=$ phosphate buffered saline; $\mathbb{\$}=$ fibronectin $140 \mathrm{kDa}$ cell binding fragment. $H P F=$ high power field. ment, ${ }^{3}$ but synoviocytes treated with anti-fibronectin Fab' appeared sparse but retained a focused morphology and did not appear rounded.

\section{Discussion}

Previous immunohistochemical and biochemical studies demonstrated the presence of multiple extracellular matrix proteins in synovium. It is assumed that synoviocytes, like other fibroblastic cells, attach predominantly to extracellular matrix fibronectin and that this attachment is important in subsequent cell spreading, migration, and proliferation. We utilised a system which examined the interactions of synoviocytes cultured in serum free medium with various extracellular matrix substrata in order to determine the effect of individual matrix preparations on synoviocyte attachment, spreading, and proliferation in vitro. Synoviocyte attachment to all extracellular matrix preparations studied was superior to that on tissue culture plastic. While initial attachment to plastic was poor, it approached $30 \%$ with time, probably secondary to secretion of extracellular matrix by the attached cells because, under these conditions, synoviocytes produce a fibronectin rich matrix. ${ }^{3}$ Although synoviocytes attached to fibronectin, their attachment was approximately $20 \%$ less than that of laryngeal fibroblasts. This suggests that synoviocyte fibronectin receptors may be of somewhat lower affinity than other connective tissue fibroblasts. Although initial synoviocyte attachment to fibronectin was not as great as that of LFB, synoviocytes were able to be maintained in culture for 28 days in serum free defined medium on a variety of matrix substrata, whereas LFB survived only 14 days. As synoviocytes demonstrate enhanced proliferation on fibronectin (fig 4), it appears that effects of fibronectin on initial synoviocyte attachment and long term growth are dissociated. Synoviocytes also demonstrated enhanced proliferation on SCFM which contained significant quantities of fibronectin. ${ }^{6}$ The addition of purified collagen I to fibronectin in vitro inhibited cell proliferation (fig 5); however, the fibronectin present in SCFM must be accessible to cell surface receptors, as the $140 \mathrm{kDa}$ cell binding fragment specifically blocked growth on SCFM and on purified fibronectin (fig 7). Collagen VI, which constitutes approximately $15 \%$ of SCFM protein, also contains multiple RGD sequences, interacts with integrin cell surface receptors, ${ }^{8}$ and may play an important role in synoviocyte growth. The failure of LFB and HFL-1 cells to exhibit long term proliferation on SCFM suggests that the proliferative response of synoviocytes to SCFM may be relatively specific.

Surprisingly, incubation of synoviocytes with antifibronectin IgG further enhanced proliferation (fig 6). Because these cells are known to display both a disorganised, overlapping morphology ${ }^{23}$ and a disorganised fibronectin matrix, ${ }^{9}$ it is possible that treatment with 
bivalent antifibronectin results in the stabilisation of aberrant fibronectin-synoviocyte interactions and thus enhanced proliferation. In contrast, antifibronectin Fab' inhibited proliferation, suggesting that bivalent cross linking of matrix fibronectin by intact antifibronectin IgG was necessary to stabilise synoviocytematrix interactions.

Previous experiments with the RGDS fibronectin cell binding tetrapeptide resulted in cell rounding and detachment. ${ }^{3}$ Incubation of synoviocytes with the $140 \mathrm{kDa}$ fragment to determine if the antifibronectin effect was attributable to blocking interaction at the RGD dependent cell binding site (fig 7) also resulted in growth inhibition caused by cell rounding and detachment. Taken together, these experiments suggest that abnormal interactions between the synoviocyte and its fibronectin matrix (summarised in figure 9) result in abnormal morphology and relative growth inhibition by a mechanism not directly involving the $\alpha 5 \beta 1$ fibronectin receptor.

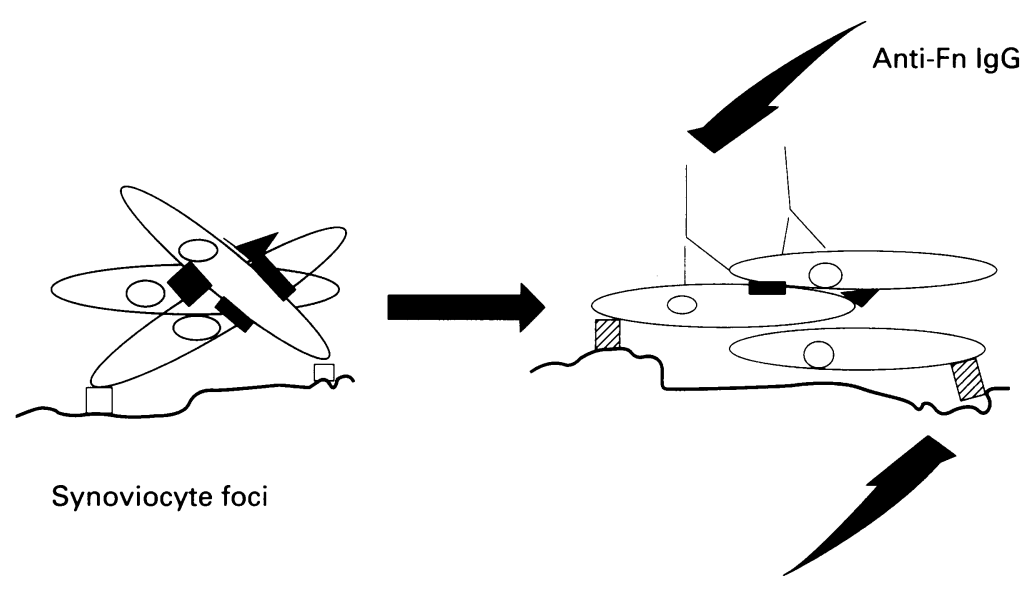

Figure 9 Proposed mechanism of growth enhancement by antifibronectin (Anti-Fn) Ig Intact IgG may stabilise disorganised fibronectin matrix on dorsum of cell (black rectangles) while not interfering with cell-substrate attachment (open and cross-hatched rectangles). The $140 \mathrm{kDa}$ cell binding fragment and the RGDS peptide interrupt cell-substrate attachment, causing rounding, detachment, and growth inhibition.
Immunohistological studies of synovium have revealed a marked increase of fibronectin, collagen VI, and other matrix components in the proliferated intimal lining. ${ }^{10-12}$ It is likely that synoviocyte-matrix interactions are important in regulating synoviocyte proliferation, adhesion, and invasion. The in vitro studies reported here demonstrate that synoviocytes interact differently with various matrix substrata, may differ from other fibroblastic cells in their interactions with matrix components, and have interactions with fibronectin and biomatrices which are complex and likely to involve multiple receptor sites. Studies of synoviocyte-matrix interactions in vitro appear to be useful in the elucidation of mechanisms controlling pannus development and cartilage invasion.

1 Ruoslahti E, Pierschbacher M D. New perspectives in cell adhesion: RGD and integrins. Science 1987; 238: 491-7.

2 Lafyatis R, Remmers E F, Roberts A B, Yocum D E, Sporn M B, Wilder R L. Anchorange-independent growth of synoviocytes from arthritic and normal joints. 7 Clin of synoviocytes from arth

3 Wolf J, Carsons S E. Fibronectin mediates anchoragedependent focus formation in cultured human synoviocytes. Semin Arth Rheum 1992; 21: 387-92.

4 West D C, Sattar A, Kumar S. A simplified in situ solubilization procedure for the determination of DNA and cell number in tissue cultured mammalian cells. Analyt Biochem 1985; 147: 289-95.

5 Carsons S, Lavietes B B, Diamond H S, Kinney S G. The immunoreactivity, ligand and cell-binding characteristics of rheumatoid synovial fluid fibronectin. Arthritis Rheum 1985; 28: $601-12$.

6 Wolf J, Carsons S. Synovial extracellular matrix: partial characterization and identification of type VI collagen characterization and identification of type VI
molecular forms. Clin Exp Rheum 1991; 9: 51-4.

7 Rojkind M, Gatmaitan Z, Mackensen S, Giambrone M A, Ponce P, Reid L M. Connective tissue biomatrix: its isolation and utilization for long term cultures of normal rat hepatocytes. F Cell Biol 1980; 87: 255-63.

8 Chu M-I, Zhang R-Z, Pan T, et al. Mosaic structure of globular domains in the human type VI collagen $\alpha_{3}$ chain: similarity to von Willebrand Factor fibronectin, actin, salivary proteins and aprotinin type protease inhibitors. $E M B O \mathcal{f} 1990$; 9: 385-93.

9 Lavietes B B, Carsons S E, Diamond H S, Laskin R S. Synthesis, secretion and deposition of fibronectin in cultured human synovium. Arthritis Rheum 1985; 28: cultured $1016-26$.

10 Scott D L, Delamere J P, Walton K W. The distribution of fibronectin in the pannus in rheumatoid arthritis. Brf Exp Path 1981; 62: 362-67.

11 Wolf J, Carsons S E. Distribution of type VI collagen expression in synovial tissue and cultured synoviocytes: relation to fibronectin expression. Ann Rheum Dis 1991; 50: 493-6.

12 Gay S, Gay R E, Miller E J. The collagen of the joint. Arthritis Rheum 1980; 23: 937-41. 